\title{
Qualification of the LHC Corrector Magnet Production With the CERN-Built Measurement Benches
}

\author{
C. Giloux, M. Karppinen, G. Mugnai, V. Remondino, W. Venturini-Delsolaro, P. Viret, L. Walckiers, and R. Wolf
}

\begin{abstract}
The LHC will incorporate about 7600 superconducting single aperture corrector magnets mounted in the main magnet cold masses. In order to follow up their production, we have designed and built 12 different benches for warm magnetic measurements based on rotating coils. Each bench was manufactured in two copies, one installed at the industry sites and the other kept at CERN for cross checks and monitoring of the measurement quality. These systems measure the main field, the field quality and the position and orientation of the field relative to the mechanical construction, all properties that are required for an effective use of the magnets. After calibration, the benches automatically refer the measured quantities to the mechanical interfaces used to align the correctors in the cold masses (pin holes or keys). In this paper we evaluate the global uncertainty achieved with the benches and compare the field measurements performed at room temperature in industry with measurements at $1.9 \mathrm{~K}$ performed at CERN on samples of each corrector type.
\end{abstract}

\section{INTRODUCTION}

$\mathbf{T}$ HE LHC will rely on a large number of corrector magnet circuits to trim beam parameters and to compensate the imperfections of the main magnets. Ref [1] describes in details the characteristics of the more than 7600 superconducting correctors needed for the LHC.

We report on the strategy and on the global results of quality control of all correctors at their production sites. This monitoring was accomplished by means of magnetic measurements at room temperature. Benches for magnetic measurement as those shown in Fig. 1 have been installed in 10 firms; 3 in India and 8 in Europe. For each type of magnet, two benches have been built; one installed at CERN and the second in the firm. Industry benches have been used to test the entire production, while CERN benches have allowed sampling or, in some cases, served as spares. The main goal of the measurements was to ensure that corrector modules were built within alignment tolerances for magnet axis, main field angle and field quality. It was important to qualify in detail all correctors before installing them in the LHC cold masses, in consideration of the heavy investment lost if the final cold test [2] would conclude for a corrector change. The aim of benches installed in firms was to follow up the production according to specifications and tolerances defined by CERN. As the magnet quality checks were set as a holding point in the production process, it has been possible to react quickly to correct problems at the source. Calibrations

Manuscript received August 19, 2007.

The authors are with CERN, CH-1211 Geneva 23, Switzerland (e-mail: christian.giloux@cern.ch).

Color versions of one or more of the figures in this paper are available online at http://ieeexplore.ieee.org.

Digital Object Identifier 10.1109/TASC.2008.920566
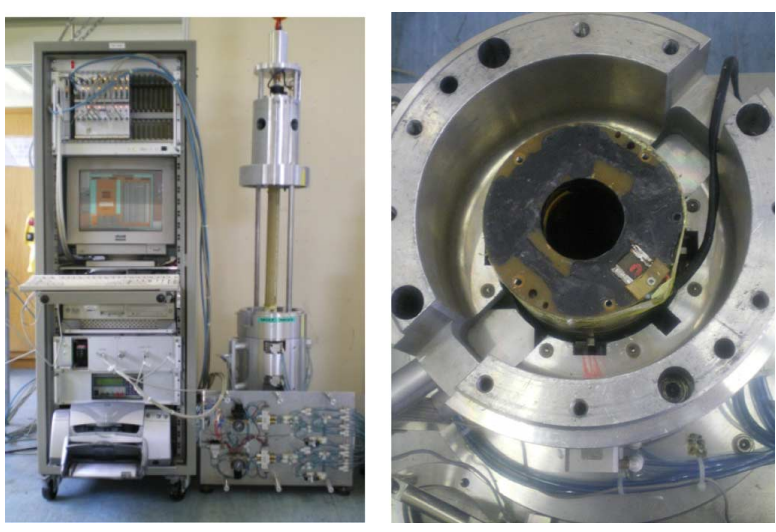

Fig. 1. Bench and control rack-A module inserted into the bench.

and measurements have been performed by industries assisted by CERN staff. A detailed procedure has been established by CERN and the benches were checked periodically by measuring reference magnets. The procedure required training of operators as well as the respect of some environmental conditions, such as a clean area without temperature fluctuations.

\section{EVALUATION OF GLOBAL UNCERTAINTIES}

\section{A. Measurement System}

The shaft: The field orientation and the axis position errors of magnet modules were measured by means of rotating coils mounted on fiberglass shafts. Each shaft was composed of one to five sectors equipped with $260 \mathrm{~mm}$ long coils in order to cover the magnet length as shown in Fig. 2(a). Each sector contained two measuring coils, one of which served as a spare (Fig. 2(b)).

\section{B. Factors of Uncertainty}

The main contributions to the systematic error come from coil positioning during rotation, coil geometry [3], mechanical tolerances of the bench, accuracy and drift of the power supply. Each device used was chosen to avoid that its systematic errors dominate the final result.

Random errors mainly arise from the positioning of magnets in the bench, which was done either by pins [4] or by industrial pneumatic grippers and keys.

The keys mounted for the measurement are the keys locking the single aperture correctors in the final twin aperture structure.

The systematic and random errors were investigated experimentally and estimated for each bench. 


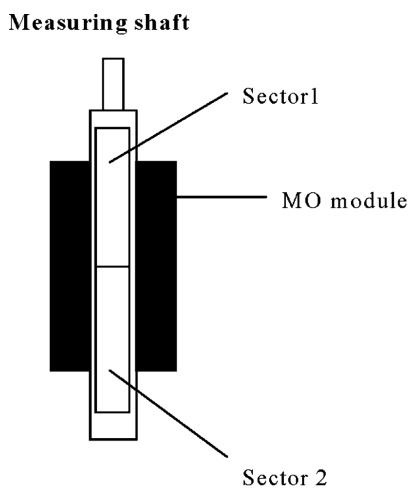

(a)

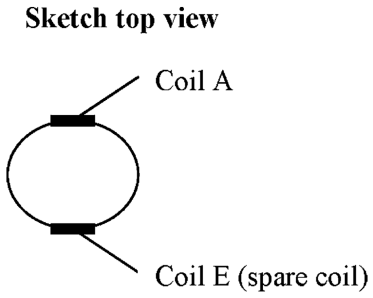

(b)
Fig. 2. (a) Shaft with 2 sectors. (b) Arrangement of the tangential coils in one sector.

TABLE I

REQUIREMENTS FOR A NEW BENCH CALIBRATION

\begin{tabular}{lcccc}
\hline & $d X(\mathrm{~mm})$ & $d Y(\mathrm{~mm})$ & $d \theta$ (mrad) & $\begin{array}{c}\text { Main Field } \\
(\mathrm{Tm} / \mathrm{A})\end{array}$ \\
\hline $\begin{array}{c}\text { Magnet values } \\
\text { Tolerance }\end{array}$ & 0.1 & 0.1 & 3.5 & $\pm 1 \%$ \\
Bench tolerance & \pm 0.015 & \pm 0.015 & \pm 0.15 & \\
\hline
\end{tabular}

\section{The Test Quality Procedure}

Twin benches have been assembled and commissioned at CERN for each magnet type. A detailed comparison on a reference corrector was done to quantify the reproducibility and systematic errors between the twin benches.

After installation in the firms, the reliability of measurement results was checked all along the production by means of the reference magnets used for calibration of the bench. Calibrations could drift due to environmental conditions and wrong manipulations. The known reproducibility (standard deviation of repeated measurements) of the bench calibration values has been used to decide when the calibration had to be renewed: the reference magnet was re-measured before each measurement campaign, and if its average $\mathrm{dX}, \mathrm{dY}$ and $\mathrm{d} \theta$ were found to exceed $\pm 0.015 \mathrm{~mm}$ and $\pm 0.15 \mathrm{mrad}$ with respect to reference values defined during commissioning, the industry operators were required to perform a new calibration in order to define new bench values.

Table I gives a summary of tolerances for magnet alignment values, i.e. offsets between magnetic and mechanical axis, roll angle errors, and main field. Tolerance values were typically $\pm 0.1 \mathrm{~mm}$ for $\mathrm{dX}, \mathrm{dY}, \pm 3.5 \mathrm{mrad}$ for $\mathrm{d} \theta$, and $1 \%$ for the spread of the main field [5]. These limits gave an indication of whether a magnet should be accepted or rejected.

\section{Calibration and Measurement}

The rotating coil technique gives the multipole fields in the reference frame of the coil rotation axis. Magnetic axis coordinates of multipole fields are derived by feed down [6].

Magnet self-alignment errors, usually called magnet parameters are given by the magnetic axis position in the magnet mechanical frame as defined by keys or holes. To determine the

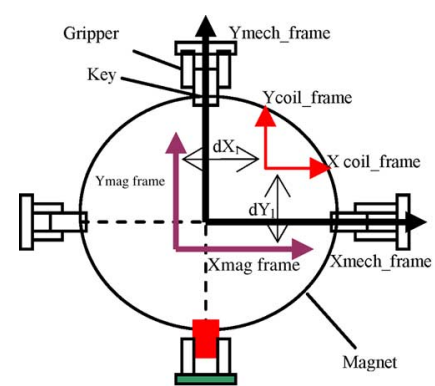

(a)

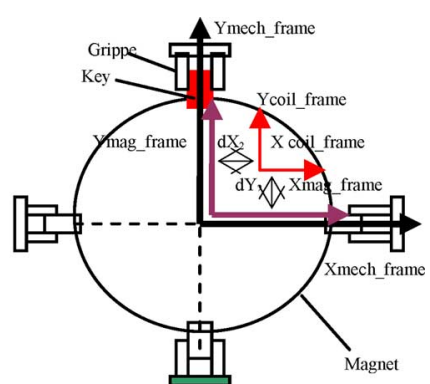

(b)
Fig. 3. (a) Axis offset pos. 1. (b) Axis offset pos. 2.

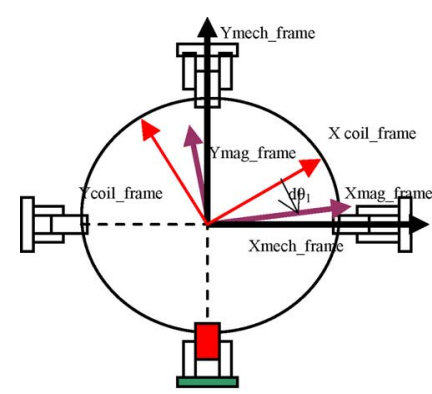

(a)

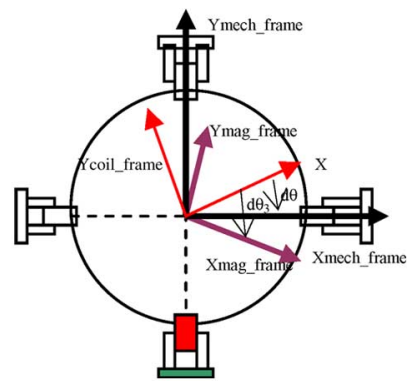

(b)
Fig. 4. (a) Angular offset pos. 1. (b) Angular offset pos. 3.

magnet parameters, it is necessary to know the bench calibration values, also called bench parameters, i.e. the position of the measuring coil with respect to the mechanical frame of the bench.

1) Calibration: (Bench Parameters): The bench parameters are defined by the position of the measuring coil with respect to the bench mechanical frame, which can be identified with the magnet mechanical frame.

To calibrate the bench, a reference magnet was measured in three different positions:

- two positions (P1-P2) described in Figs. 3(a) and 3(b), with $\mathrm{P} 2$ rotated by $180^{\circ}$ with respect to the normal position $\mathrm{P} 1$, to measure axis offsets $\left(\mathrm{dX}_{\text {Bench }}, \mathrm{dY}_{\text {Bench }}\right)$

- two positions (P1-P3) described in Figs. 4(a) and 4(b), with $\mathrm{P} 3$ turned end to end with respect to P1, to measure the angular offset $\left(\mathrm{d} \theta_{\text {Bench }}\right)$.

The result is given by the following operations:

$$
\begin{aligned}
& \mathrm{dX}_{\text {Bench }}=\left(\mathrm{dX}_{1}^{ \pm \sigma} \times 1+\mathrm{dX}_{2} \pm \sigma \times 2\right) / 2 \\
& \mathrm{dY}_{\text {Bench }}=\left(\mathrm{dY}_{1} \pm \sigma_{\mathrm{y} 1}+\mathrm{dY}_{2} \pm \sigma_{\mathrm{y} 2}\right) / 2 \\
& \mathrm{~d} \theta_{\text {Bench }}=\left(\mathrm{d} \theta_{1}{ }^{ \pm \sigma} \sigma_{\theta 1}+\mathrm{d} \theta_{3}{ }^{ \pm \sigma}{ }_{\theta 3}\right) / 2
\end{aligned}
$$

where the indexes 1, 2 and 3 refer to the three measurement positions, and we have superscripted the uncertainties $\sigma$ due to random errors affecting each quantity. This sequence of three measurements is referred to as a calibration process.

Calibration processes are time consuming, and their contribution to the global uncertainty decreases with their number (see 
TABLE II

BENCH REPRODUCIBILITY FOR MO, MS AND MQTL BENCHES

\begin{tabular}{|c|c|c|c|c|c|c|c|c|c|}
\hline & & $\mathrm{MO}$ & & & MS & & & MQTL & \\
\hline & $\begin{array}{l}\text { Bench } 1 \\
\text { Indust. }\end{array}$ & $\begin{array}{c}\text { Bench } 2 \\
\text { Cern }\end{array}$ & Diff & $\begin{array}{l}\text { Bench } 1 \\
\text { Indust. }\end{array}$ & $\begin{array}{c}\text { Bench } 2 \\
\text { Cern }\end{array}$ & Diff & $\begin{array}{l}\text { Bench1 } \\
\text { Indust. }\end{array}$ & $\begin{array}{c}\text { Bench } 2 \\
\text { Cern }\end{array}$ & Diff \\
\hline dX_Av(mm) & -0.006 & -0.015 & 0.009 & -0.070 & -0.081 & 0.011 & 0.030 & 0.04 & 0.010 \\
\hline dY_Av(mm) & 0.018 & 0.014 & 0.004 & -0.009 & -0.014 & 0.005 & 0.061 & 0.065 & 0.005 \\
\hline $\mathrm{d} \theta \_\mathrm{Av}(\mathrm{mrad})$ & 0.185 & 0.256 & 0.072 & -1.209 & -1.138 & 0.071 & -0.79 & -0.746 & 0.044 \\
\hline$\sigma(\mathrm{dX})(\mathrm{mm})$ & 0.013 & 0.005 & & 0.010 & 0.018 & & 0.006 & 0.009 & \\
\hline$\sigma(\mathrm{dY})(\mathrm{mm})$ & 0.004 & 0.008 & & 0.009 & 0.006 & & 0.009 & 0.008 & \\
\hline$\sigma(\mathrm{d} \theta)(\mathrm{mrad})$ & 0.108 & 0.100 & & 0.029 & 0.138 & & 0.046 & 0.145 & \\
\hline
\end{tabular}

TABLE III

BENCH REPRODUCIBILITY FOR MQT, MCBC AND MCB BENCHES

\begin{tabular}{|c|c|c|c|c|c|c|c|c|c|}
\hline & \multicolumn{3}{|c|}{ MQT/S } & \multicolumn{3}{|c|}{$\mathrm{MCBC}$} & \multicolumn{3}{|c|}{ MCB } \\
\hline & $\begin{array}{l}\text { Bench 1 } \\
\text { Indust. }\end{array}$ & $\begin{array}{l}\text { Bench2 } \\
\text { CERN }\end{array}$ & Diff & $\begin{array}{l}\text { Bench1 } \\
\text { Indust. }\end{array}$ & $\begin{array}{l}\text { Bench 2 } \\
\text { CERN }\end{array}$ & Diff & $\begin{array}{l}\text { Bench1 } \\
\text { Indust. }\end{array}$ & $\begin{array}{c}\text { Bench } 2 \\
\text { CERN }\end{array}$ & Diff \\
\hline $\begin{array}{c}\mathrm{dX} \_\mathrm{Av} \\
(\mathrm{mm})\end{array}$ & 0.116 & 0.142 & 0.026 & & & & & & \\
\hline $\begin{array}{c}\text { dY_Av } \\
(\mathrm{mm}\end{array}$ & 0.006 & 0.021 & 0.015 & & & & & & \\
\hline $\begin{array}{l}\mathrm{d} \theta \_\mathrm{Av} \\
(\mathrm{mrad})\end{array}$ & -0.270 & -0.121 & 0.149 & -0.555 & -0.629 & 0.074 & -0.741 & -0.766 & 0.025 \\
\hline $\begin{array}{c}\sigma(\mathrm{dX}) \\
(\mathrm{mm})\end{array}$ & 0.005 & 0.007 & & & & & & & \\
\hline $\begin{array}{c}\sigma(\mathrm{dY}) \\
(\mathrm{mm})\end{array}$ & 0.006 & 0.006 & & & & & & & \\
\hline $\begin{array}{c}\sigma(\mathrm{d} \theta) \\
(\mathrm{mrad}) \\
\end{array}$ & 0.064 & 0.063 & & 0.039 & 0.054 & & 0.034 & 0.024 & \\
\hline
\end{tabular}

below). The number of processes was set to 5 , in which case the standard error on the bench parameters is:

$$
\begin{aligned}
\sigma_{\mathrm{x}} & =\frac{1}{\sqrt{5}} \sqrt{\frac{1}{4}\left(\sigma_{\mathrm{x} 1}^{2}+\sigma_{\mathrm{x} 2}^{2}\right)} \sigma_{\mathrm{y}}=\frac{1}{\sqrt{5}} \sqrt{\frac{1}{4}\left(\sigma_{\mathrm{y} 1}^{2}+\sigma_{\mathrm{y} 2}^{2}\right)} \sigma_{\mathrm{T}} \\
& =\frac{1}{\sqrt{5}} \sqrt{\frac{1}{4}\left(\sigma_{\theta 1}^{2}+\sigma_{\theta 3}^{2}\right)}
\end{aligned}
$$

2) Measurement: (Magnet Parameters): Knowing the bench parameters, raw measurement results can be corrected to deduce magnet parameters as follows:

$$
\begin{aligned}
& \mathrm{dX}_{\text {magnet }}=\left(\mathrm{dX}_{\text {meas }}{ }_{\mathrm{xm}}-\mathrm{dX}_{\text {Bench }}{ }^{ \pm \sigma}{ }_{\mathrm{x}}\right) \\
& \mathrm{d} \mathrm{Y}_{\text {magnet }}=\left(\mathrm{d} \mathrm{Y}_{\text {meas }}{ }_{\mathrm{ym}}{ }_{\mathrm{ym}}-\mathrm{d} \mathrm{Y}_{\text {Bench }}{ }_{\mathrm{y}} \sigma_{\mathrm{y}}\right) \\
& \mathrm{d} \theta_{\text {magnet }}=\left(\mathrm{d} \theta_{\text {meas }}{ }_{\theta \sigma}-\mathrm{d} \theta_{\text {Bench }}{ }_{\theta} \sigma_{\theta}\right)
\end{aligned}
$$

The combined uncertainties due to random errors on magnet parameters are then:

$$
\begin{aligned}
& \sigma_{\mathrm{x} \_\mathrm{mag}}=\sqrt{\sigma_{\mathrm{xm}}^{2}+\frac{1}{20}\left(\sigma_{\mathrm{x} 1}^{2}+\sigma_{\mathrm{x} 2}^{2}\right)} \\
& \sigma_{\mathrm{y} \_\mathrm{mag}}=\sqrt{\sigma_{\mathrm{ym}}^{2}+\frac{1}{20}\left(\sigma_{\mathrm{y} 1}^{2}+\sigma_{\mathrm{y} 2}^{2}\right)} \\
& \sigma_{\theta \_\mathrm{mag}}=\sqrt{\sigma_{\theta \mathrm{m}}^{2}+\frac{1}{20}\left(\sigma_{\theta 1}^{2}+\sigma_{\theta 3}^{2}\right)}
\end{aligned}
$$

Magnet parameters (magnet axis position and roll angle) define the magnetic frame with respect to the magnet mechanical frame:

$$
\begin{aligned}
& \mathrm{dX}_{\text {magnet }} \pm \sigma x_{\text {_mag }} \\
& \mathrm{dY}_{\text {magnet }} \pm \sigma \mathrm{y}_{\text {mag }} \\
& \mathrm{d} \theta_{\text {magnet }} \pm \sigma \theta_{\text {_mag }}
\end{aligned}
$$

Assuming that the error distributions for the three measurement positions have the same standard deviation, we can write:

$$
\begin{aligned}
& \sigma_{\mathrm{x} \_ \text {mag }}=\sigma_{\mathrm{x} \_\mathrm{m}} \sqrt{\frac{11}{10}} \quad \sigma_{\mathrm{y} \_ \text {mag }}=\sigma_{\mathrm{y} \_\mathrm{m}} \sqrt{\frac{11}{10}} \\
& \sigma_{\theta_{-} \mathrm{mag}}=\sigma_{\theta_{-\mathrm{m}}} \sqrt{\frac{11}{10}}
\end{aligned}
$$

This shows that the combined uncertainty from calibration and measurement is dominated by the error associated with the measurement, which cannot be reduced unless a larger number of measurements is performed. Results are given sector by sector, and sectors are then averaged to obtain the magnet results. As the correlation coefficients among sectors are not zero (sectors being fixed on the same support), they were estimated from the results of repeated measurements, to compute the uncertainties shown in Tables II and III. 
TABLE IV

MEASUREd AlignMENT ERRORS FOR SERIES MOdULES

\begin{tabular}{ccccccccc}
\hline \hline $\begin{array}{c}\text { Module } \\
\text { Type }\end{array}$ & $\begin{array}{c}\text { Target } \\
\text { Module } \\
\text { Production }\end{array}$ & $\begin{array}{c}\text { Number } \\
\text { of meas. }\end{array}$ & $\mathrm{dX}$ mag. & $\sigma(\mathrm{X})$ & $\mathrm{d} \mathrm{Y}_{\text {mag. }}$ & $\sigma(\mathrm{Y})$ & $\mathrm{d} \theta_{\text {mag. }}$ & $\sigma(\theta)$ \\
\hline MCBC & 156 & 245 & & & & & & \\
$(\mathrm{~mm})$ & $(\mathrm{mm})$ & $(\mathrm{mm})$ & $(\mathrm{mrad})$ & $(\mathrm{mrad})$ \\
MCBM & 752 & 824 & & & & & 0.10 & 2.47 \\
MCBY & 88 & 101 & & & & & & \\
MO & 376 & 370 & -0.012 & 0.036 & 0.023 & 0.034 & 0.12 & 0.99 \\
MQS & 80 & 74 & 0.024 & 0.071 & 0.015 & 0.071 & -0.60 & 1.89 \\
MQT & 320 & 328 & 0.031 & 0.059 & 0 & 0.059 & -0.53 & 1.58 \\
MQTL & 120 & 273 & -0.019 & 0.077 & 0.018 & 0.09 & -0.054 & 1.68 \\
MSM & 752 & 764 & -0.01 & 0.048 & -0.009 & 0.048 & 0.55 & 1.72 \\
\hline \hline
\end{tabular}

\section{E. Evaluation of Global Uncertainties}

From manufacturing tolerances, systematic errors should be in the shadow of the random errors discussed above. An indication that this is indeed the case comes when comparing results of two benches measuring a reference magnet, after calibration. Tables II and III summarize averages and standard deviations of reference magnet parameters for all types of benches with grippers.

For each bench the tables give:

- An indication of systematic effects between benches in industry and CERN (in the column Diff). For dX_Av and dY_Av, differences ranged from 0.004 to $0.011 \mathrm{~mm}$, for MO, MS and MQTL benches. For the MQT/S bench the difference is larger, from 0.015 to $0.026 \mathrm{~mm}$, whereas $\mathrm{d} \theta$ differences vary from 0.025 to $0.149 \mathrm{mrad}$.

- The reproducibility, defined by standard deviations of repeated measurements, ranging from 0.004 to $0.018 \mathrm{~mm}$ for $\mathrm{dX}$ and $\mathrm{dY}$, and from 0.024 to $0.145 \mathrm{mrad}$ for $\mathrm{d} \theta$.

In conclusion, systematic differences of results between two benches are comparable with the standard deviations of repeated measurements.

The estimated systematic error and the random error, assumed uncorrelated, are combined in a global uncertainty by quadratic addition [7].

\section{Summary Of Series Measurements Results}

After bench installation and commissioning, measurement campaigns have been carried out during production at the industry sites since the end of 2002. The last corrector was measured at the end of 2006. Results are summarized in Table IV, which reports population averages and standard deviations of magnet parameters.

As shown in Table IV, population spreads are significantly higher that uncertainties listed in Tables II and III, indicating that the benches could discriminate between different magnets within the production. More importantly, global uncertainties were significantly lower than tolerances given in Table I, which allowed accepting or rejecting magnets on a solid basis.
Thanks to magnetic measurements, drifts in tooling and manufacturing errors could be detected and corrected almost in real time. Special keys have been machined to correct the field direction found out of tolerance on some correctors, which helped to reduce the number of rejected magnets for all types. The total number of measurements stored in the database, including those of spool piece correctors not treated in this paper, approaches 8500 .

\section{Comparison of Main Field Values Measured AT RoOM TEMPERATURE With THE FIELD MEASURED AT CRYOGENIC TEMPERATURE $(1.9 \mathrm{~K})$}

In the industries all magnets were measured at room temperature. The excitation current used was between $0.1 \mathrm{~A}$ and $1 \mathrm{~A}$ depending on the magnet type [8], whereas cold measurements were performed on a small sample of magnets at different current values from zero to nominal current. In order to effectively use the magnets in the LHC, it is necessary to know the correlation between warm and cold measurements. The following table (Table $\mathrm{V}$ ) shows, for small samples of $\mathrm{N}$ magnets measured at cold, the results of warm and cold measurement averages and spreads of the main harmonic and the relative offset between warm and cold. The offset ranges from -1.27 to $2.3 \%$, except for MCB, for which the length of measurement coil in the warm bench did not fully cover the magnet. The absolute determination of magnetic fields at warm was considered not necessary; the warm coils were therefore not calibrated: warm measurements need only to provide a homogeneous set of data to be correlated with cold measurements. Standard deviations range from $0.05 \%$ to $2.23 \%$, with a peak of $16.5 \%$ for MO magnets. It was decided not to calibrate the measuring shafts for the sensitivity to the octupole.

In Fig. 5 for each main field average point the standard deviation bar was multiplied by 20 to visualize "population spreads" at warm and cold temperature.

In two cases (MS and MO) the spreads at cold are bigg02-chouhaner than the spreads at warm and in three other cases the spreads at cold and warm are similar. The MCB 
TABLE V

CORRECTOR MAIn Field MEASURED AT RoOM AND CRYOGENIC TEMPERATURES

\begin{tabular}{ccccccc}
\hline \hline & Sample & \multicolumn{2}{c}{ Warm measurement } & \multicolumn{3}{c}{ Cold measurement } \\
\hline \hline & $\mathrm{N}$ & $\begin{array}{c}\text { Average } \\
(\mathrm{Tm} / \mathrm{A})\end{array}$ & $\begin{array}{c}\sigma \\
\%\end{array}$ & $\begin{array}{c}\text { Average } \\
(\mathrm{Tm} / \mathrm{A})\end{array}$ & $\begin{array}{c}\sigma \\
\%\end{array}$ & $\begin{array}{c}\text { Offset } \\
\%\end{array}$ \\
\hline $\mathrm{MS}$ & 4 & $9.07 \mathrm{E}-04$ & 0.05 & $8.94 \mathrm{E}-04$ & 1.35 & 1.46 \\
$\mathrm{MQT}$ & 12 & $1.30 \mathrm{E}-03$ & 0.90 & $1.35 \mathrm{E}-03$ & 0.90 & -1.27 \\
$\mathrm{MO}$ & 5 & $1.79 \mathrm{E}-03$ & 1.1 & $1.80 \mathrm{E}-03$ & 16.5 & -0.67 \\
$\mathrm{MCBX}$ & 8 & $2.99 \mathrm{E}$ & 0.28 & $2.93 \mathrm{E}-03$ & 0.17 & 2 \\
$\begin{array}{c}\text { Inner) } \\
\text { MCBX } \\
\text { (outer) }\end{array}$ & 5 & $3.18 \mathrm{E}-03$ & 0.10 & $3.11 \mathrm{E}-03$ & 0.12 & 2.3 \\
MCB & 11 & $3.07 \mathrm{E}-02$ & 0.32 & $13.37 \mathrm{E}-02$ & 2.23 & -9.6 \\
\hline \hline
\end{tabular}

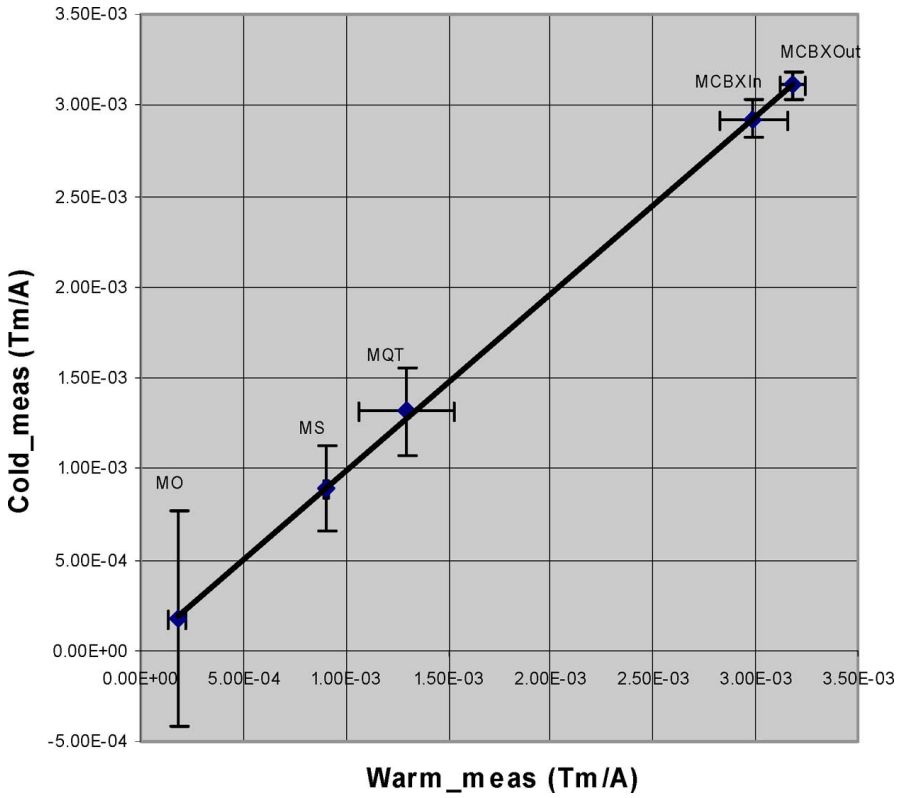

Fig. 5. Main harmonic and standard deviation for different magnet types. The Error bars are multiplied by 20 to be readable.

point does not appear in the graph, its magnitude being 10 times bigger than MCBX points, due to the much higher number of turns of MCB magnets.

All points fall onto a straight line of slope 1 passing through the origin.

\section{CONCLUSIONS}

The benches for magnetic measurements set up by CERN for quality monitoring of LHC correctors in industry met the accuracy requirements for which they had been designed. The normal staff of the manufacturers has successfully operated them for the whole magnet production due to their simplicity of operation and easy maintenance. This allowed accepting or rejecting modules according to predefined tolerances.
The benefits brought to the project by systematic warm measurements of all corrector modules at the production sites were significant. Besides early spotting of gross errors (like polarity mistakes) and tooling drifts, in many cases it was possible to identify and correct alignment and angle errors, which resulted in a much reduced waste rate.

The cold magnetic measurement samples allow estimating the relative offsets between warm and cold field values.

\section{ACKNOWLEDGMENT}

The authors are grateful to the teams in Block 4, particularly Jérome Feuvrier, who has performed most warm magnetic measurement at CERN, Hubert Reymond (AB-CO) who wrote the measurement software and Diogo Rodrigues and Helder A. Lopes (MEL quality control inspectors).

\section{REFERENCES}

[1] O. Brüning, P. Collier, P. Lebrun, S. Myers, R. Ostojic, J. Poole, and P. Proudlock, "LHC Design Report v.1: The LHC Main Ring," CERN, Geneva, 2004.

[2] V. Chohan et al., LHC-PROJECT-Report-984: Operation for LHC Cryomagnet Tests CERN, Geneva, Feb. 22, 2007.

[3] S. Turner, "CAS-CERN Accelerator School: Measurement and Alignment of Accelerator and Detector Magnets," Anacapri, Italy, CERN-98-05, Apr. 11-17, 1997, 1998 Geneva.

[4] A. Arn, A. Arshad, C. Giloux, F. Patru, H. Raymond, R. Senis, and L. Walckiers, "The measurement bench for the LHC spool corrector magnets in industry," presented at the 2003 Int. Conf. Magnet Technology (MT 17), Morioka, Japan, Oct. 20-24, 2003.

[5] M. Allitt, M. Bagre, C. Giloux, M. Karppinen, P. Khare, A. Lombardini, T. Maurya, A. Puntambekar, V. Remondino, A. S. Badal, W. V. Delsolaro, and R. Wolf, "Field quality hysteresis of the LHC superconducting corrector magnets," presented at the 9th Eur. Particle Accelerator Conf. (EPAC'04), Lucerne, Switzerland, Jul. 5-9, 2004.

[6] L. Bottura, "Standard analysis procedures for field quality measurement of the LHC magnets," Internal Note February 2, 2000.

[7] Guide to the Expression of Uncertainty of Measurement (1993) by International Bureau of Weights and Measures, 1st ed. Geneva, Switzerland: ISO, 91-67-10188-9.

[8] M. Allitt, A. Ijspeert, M. Karppinen, J. Mazet, and R. Wolf, "Status of the production of the LHC superconducting correctors magnets," presented at the 2003 Int. Conf. Magnet Technology (MT 18), Morioka, Japan, Oct. 20-24, 2003. 